Original Research Article

\title{
Repetition Values on Martin Luther King Jr. Speech
}

Mas Darul Ihsan*

Faculty of Literature, University of Gresik, Indonesia

Jl. Arief Rahman Hakim 2B, Gresik, Indonesia. Tel: 62-877-5414-1325.

Article History:

Submitted: $7^{\text {th }}$ December 2017, Accepted: $27^{\text {th }}$ September 2018, Published: $15^{\text {th }}$ October 2018

\begin{abstract}
There are so many speeches delivered by such famous people in this world. But, if we are asked to give the point of view about the impact of each speech delivered then the speech from Martin Luther King Jr. will convey the high meaning in term of rethorical speech especially the content and the context about the concepts of repetition found. The speech was on 28th of August 1963, at the Lincoln Memorial, Washington D.C in a verbal ways and its text become the secondary data to be analyzed with much focus on emphasizing phrases, words or sentences. By using the concept of rethoric perspective through repetition such as anaphora, epistrophe and epizeuzis, the researcher wants to know the values behind the repetition. That is why, the analysis is using the descriptive qualitative research on taking the secondary data that has been adapted from the video and the text of the speech itself. The conclusion especially on the ideas of repetition are that Martin Luther King Jr. tries to make sure his audiences about that 1) the repetition is something more that the meaning itself, it is above. 2) The struggle, it is something true, needs to be realized in the real life, and adds the weight of the expection to be equal and free.
\end{abstract}

Keywords: rhetoric perspective; repetition; repeat key; speech; true.

HOW TO CITE: Ihsan, M. (2018). Repetition Values on Martin Luther King Jr. Speech. JEES (Journal of English Educators Society), 3 (2), 177-188. doi: https://doi.org/10.21070/jees.v3i2.1236

\section{Introduction}

The speech from Martin Luther King Jr. on exactly 28th of August 1963, at the place with well-known as Lincoln Memorial, Washington D.C entitled "I Have a Dream" become one of the most unforgettable, undeniable or unavoidable among speeches from all over the world. This speech becomes the evergreen and everlasting masterpiece in seeing the speech as the part of the world history. Then, this will be something worthy that the speech approximately by the end of the century of twentieth, precisely in December the year of 1999, the American,

E-mail address: masdarulihsan2@gmail.com

Peer reviewed under reponsibility of Universitas Muhammadiyah Sidoarjo.

(C) 2018 Universitas Muhammadiyah Sidoarjo, All right reserved, This is an open access article under

the CC BY license (http://creativecommons.org/licenses/by/4.0/) 
as the subject of the speech at that time, called this speech by giving the honour as the best American speeches among around more than 100 (one hundred) selected speeches, and that was The American Rethoric community. This community officially consists of 137 leading board scholar who was giving the ranking among the speeches, again, from the duration time at the century of twenty. One of the criteria proposed in giving the scoring was based on the impact on social and political derivation, and artistary of the rhetorical itself. The final decision went to "I have a Dream" speech.

One of the speech point delivered by Martin Luther King Jr. is that there are so many rethorical strategies in which with verbal, orally tried to hold tightly the concept of Americal Civil Religion in a corelation with the American itself for there are so many system conducted at that time, neglect the constitutional system, that was why the speech tried to with verbal, orally to subvert the power, according the Martin Luther King Jr., the invisible system. This is also supported by Asmaradhani (2007) who says that the speech of Martin Luther King Jr. reflects so many rethorical devices need to be analyse, but he did not focus on the concept of repetition.

Therefore, from that above introduction, the researcher, after watching the video, analyzing the detail of the speech conveyed, found so many repetition, utterances, words, and sentences, from that oral speech. Then, there come the ideas that the research question of this research among the rethorical strategies conveyed by Martin Luther King Jr. is: what are the repetition values on Martin Luther King Jr. speech.

Furthermore, seeing the concept of style, belief and register as one of the partial code of the every single speaker who wants to speak is that, the every single of speaker proposed to have his/her own ways of speaking. Those cannot be denied that the uniqueness ways of speaking are something common but this senses of common see a little difference idea about that the style, belief, and register can be influenced by the conditions or circumstances in where the speaker available, this is the context of language, see pragmatics (Badib, 2010; Gabbay, M. Dov and Woods, 2003; Geurts, 1999; Mey, 1993; Schmitz, 2008; Yule, 1996). Seeing the concepts of pragmatics, when people talk they have the intention to communicate something to somebody. This is called communicative principle. Mey (1993) argues that "communicative principle is the foundation of all linguistics behavior and the minimal agreed-on premise of all investigation into the pragmatic activity of humans" (Bara, 2010; Chomsky, 1972).

While, the idea of pragmatics goes to the concept of rethoric itself. According to Bradford (1997), he explains that the term of rethoric is the derivation from Greek, it is techne 
rhtorike, and the meaning is the art speech, the concept is about the art deals with the usage of the public speaking as the tools, means of communication.

In a same sense, Asmaradhani (2007), there are several red-lines from the definition of rethoric, such as: first, rethoric is about the technique of finding some of the persuasive aspects of a given or certain subject matter. Second, rethoric is the effort to conduct the search or investigation and to polish some explanations, both to defend and to prosecute. Third, Rethoric is about such a treatment on how the sick, something, become healthy or a study of misunderstanding and its remidies, reveals. Next, still on the red-lines about the rethorics, that rethorics is an argumentations aims at gaining the adherence of minds. Furthermore, rethoric is not only about the usage of language as a symbolic means of inducting cooperation, but also rethoric is as the mobilization of signs for the articulation of identities, ideologies, conciousness, communities, publics, and cultures. The last, that rethoric is the art or science of using words impressively in speech and biting or in the other words, rethorics is the art of effective expression and the persuasive use of language.

According to Fix, Gardt, \& Knape (2008) in such a certain book, they say that rhetoric is known as teachings in the effective formation of language: the concepts of being motivated by a communicative tools, the speaker or author selects those linguistic devices which express the intent of his utterance most appropriately and effectively. This is also supported by Toolan (1999), he proposes that, "rhetoric saw the skill productive language, speaking and writing, are not merely as textual objects, both are to be aesthetically contemplated and endlessly deconstructed. But, certainly as forms of activity in which cannot be separated from the wider social relations between writers, speakers and readers, listener, orators and audiences, and as widely uninteligible outside the social purposes and conditions in which they were attached each other."

There are some poins of view between the ideas Badib. He says that when we are studying about rethoric, or rethorics, as a science, we must also study about its derivation, such as pragmatics, discourse, stylistics and dispotio or elocution. Those three aspects play an important role to support the understanding, or the understanding itself about the concept of rethorics. The next focus goes to stylistics, as a science. Studying stylistics needs the support of linguistics and literary criticism. (For more detailed information, see the diagram 1). 


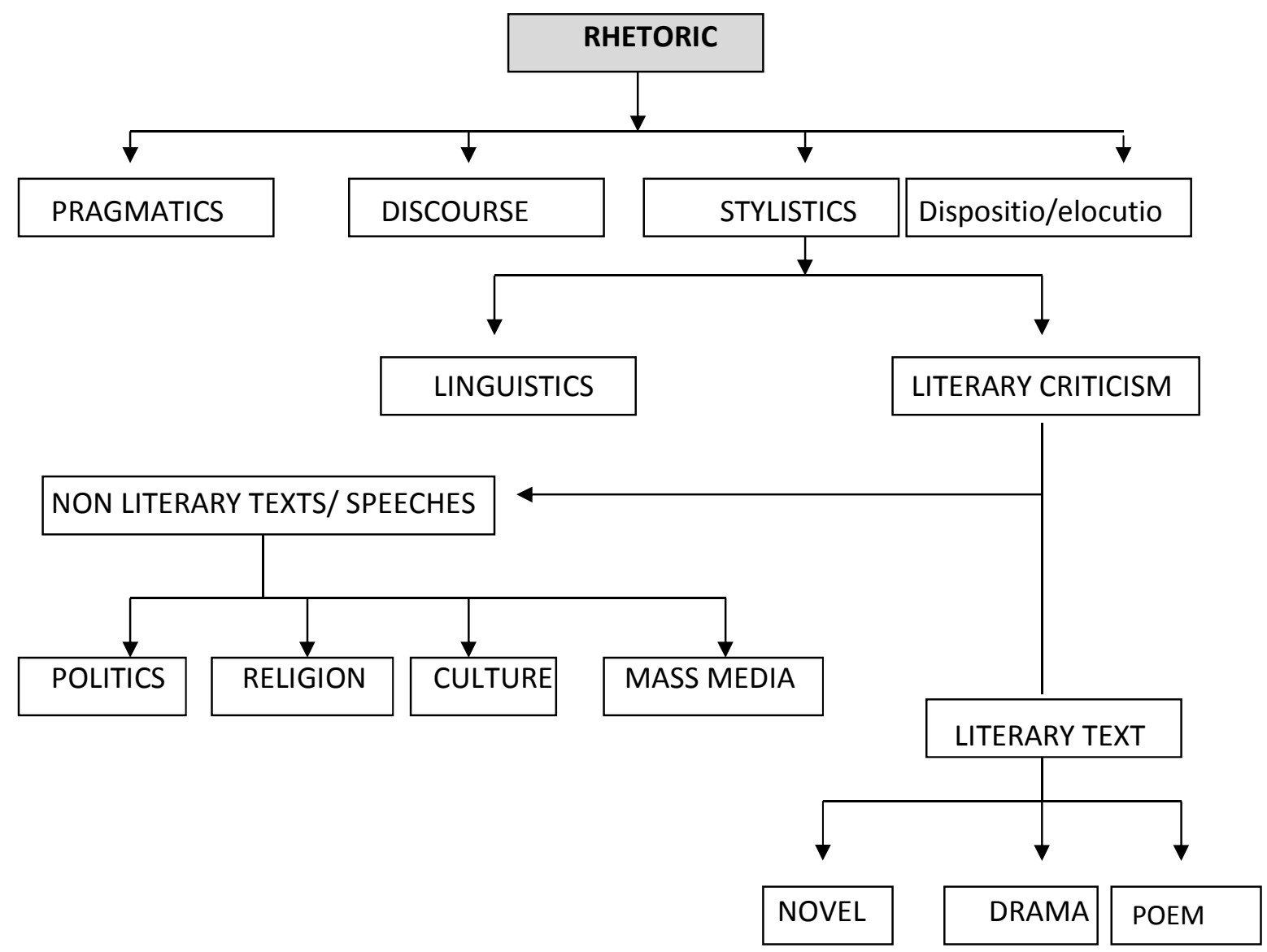

Diagram 1. Rhetoric as a science: the distribution

From the diagram above, Badib (2010) wants to explain that rethorics is as the main science needs to be understood, as the skill of productive language. To support the productive language itself, there are some pre-conditions, those are not something taken for granted but something can be or need to be studied, again, because it is about science, rethoric is a science.

The concept of rethoric has a same line with the notion of public speaking. It is because, it will be impossible for someone to apply the theory of rethoric without having the audinces, having no circumstances, and having no languages in context or the nature of language itself. Public speaking is about the public utterances, and public issuance of the people itself. He proposes that one of the stuff of public speaking, or the art of the public speaking is the voice. See, it is the voice, it can be heard, and it can be felt through the openness and forwardness. Therefore, the discussion of this research will be about the rethoric perpective through the idea of repetition values found in the speech of Martin Luther King Jr. 


\section{Methods}

The data collected from the tapping video, the video from the youtube, internet. It was the speech was from Marthin Luther King Jr. speech on 28th of August 1963, at the Lincoln Memorial, Washington D.C. The text of the speech then identified by using the descriptive qualitative research in a purposefully to the concept of the rethoric perspective through of course based on the focus discussion such as anaphora, epistrophe and epizeuzis.

The writer then tabulates the data to do the data analysis and interpretation to the specific information happened in the text. After the data analysed and interpretated, the writer validated the accuracy of the findings. The finding is based on the issues of anaphora, epistrophe and epizeuzis.

\section{Findings and Discussion}

Much discussion of this research will be about the rethoric perpective through the idea of repetition values such as anaphora, epistrophe and epizeuzis found in the speech of Martin Luther King Jr.

\section{Finding: on repetition values}

In the book, the study of language. Yule (2006) writes clearly about the definition of anaphora, that anaphora deals with the repetition. The focus of anaphora is, first, the words repetition at the beginning of neighbouring clauses, it is one of the rhetorical tool, say also device. Second, anaphora is also focusing its emphasizing on repeating the words twice sets the pattern, and its effect is on increasing the rhetorical effect, next, the rhetorical effects are about to draw the attention from the listener, audiences, or the hearers, and to convey the clear message about the language in context. Fourth, anaphora tends to use a reffering back, the purpose of this is to introduce the entity, the certain entitiy in the context of the language itself.

In a same sense, Chapman (1973) argues also about anaphora, it is also about the repetition, the repetition of word or phrases at the beginning of the chosen pattern, at the beginning of utterances. The concept of repetition sometimes occurs in a lexical manner, in which the lexical manner is repeated two times or even more. In a same line, the lexical manner is a repetition of the same lexical unit or that of lexical unit but the ideas of its morphology is different, not the same. This happen is something common in such as of political speeches, the researcher needs to say that the speech delivered by Martin Luther King Jr. is the political 
speech, that the contain of the speech, some parts of the words which essentially like to complement each other.

In a complete data, there are 9 (nine) citation. Back to the speech of Martin Luther King Jr. which have the title "I have a dream." To analyze the data, researcher uses the qualitative approach, the focus is about the object of people and situation (Creswell, 2012). In this focus, the researcher make 7 (seven) citations or data from the speech. All those citation or data are in the ideas of repetition. Below are the repetitions, in the stage of anaphora:

In a paragraph 3 (three) from the speech, the anaphora is the world: one hundred years later. This words is repeated four times in a paragraph of the speech.

Data number 1:

[3] But one hundred years later, the Negro still is not free. One hundred years later, the life of the Negro is still sadly crippled by the manacles of segregation and the chains of discrimination. One hundred years later, the Negro lives on a lonely island of poverty in the midst of a vast ocean of material prosperity. One hundred years later, the Negro is still languished in the corners of American society and finds himself an exile in his own land. And so we've come here today to dramatize a shameful condition.

In a paragraph 6 (six) from the speech, the anaphora is the world: now is the time. This words is repeated four times in a paragraph of the speech.

Data number 2:

[6] Now is the time to make real the promises of democracy. Now is the time to rise from the dark and desolate valley of segregation to the sunlit path of racial justice. Now is the time to lift our nation from the quicksands of racial injustice to the solid rock of brotherhood. Now is the time to make justice a reality for all of God's children.

In a paragraph 8 (eight) from the speech, the anaphora is the world: we must. This words is repeated four times in a paragraph of the speech.

Data number 3:

[8] we must not be guilty of wrongful deeds. Let us not seek to satisfy our thirst for freedom by drinking from the cup of bitterness and hatred. We must forever conduct our struggle on the high plane of dignity and discipline. We must not allow our creative protest to degenerate into physical violence. Again and again, we must rise to the majestic heights of meeting physical force with soul force.

In a paragraph 13 (thirteen) from the speech, the anaphora is the world: we can never be satisfied. This words is repeated seven times in a paragraph of the speech. 


\section{Data number 4:}

[13] We can never be satisfied as long as the Negro is the victim of the unspeakable horrors of police brutality. We can never be satisfied as long as our bodies, heavy with the fatigue of travel, cannot gain lodging in the motels of the highways and the hotels of the cities. We cannot be satisfied as long as the negro's basic mobility is from a smaller ghetto to a larger one. We can never be satisfied as long as our children are stripped of their self-hood and robbed of their dignity by signs stating: "For Whites Only." We cannot be satisfied as long as a Negro in Mississippi cannot vote and a Negro in New York believes he has nothing for which to vote. No, no, we are not satisfied, and we will not be satisfied until "justice rolls down like waters, and righteousness like a mighty stream."

In a paragraph 14 (fourteen) from the speech, the anaphora is the world: go back to.

This words is repeated six times in a paragraph of the speech.

Data number 5:

[14] Go back to Mississippi, go back to Alabama, go back to South Carolina, go back to Georgia, go back to Louisiana, go back to the slums and ghettos of our northern cities, knowing that somehow this situation can and will be changed.

In a paragraph 16 (fourteen) to 24 (twenty four) from the speech, the anaphora is the world: I have a dream. This words is repeated nine times in a paragraph of the speech.

Data number 6:

[16] I still have a dream. It is a dream deeply rooted in the American dream. [17]I have a dream that one day this nation will [18] I have a dream that one day on the red hills of Georgia [19] I have a dream that one day even the state of Mississippi [20] I have a dream that my four little Children [21] I have a dream today [22] I have a dream that one day, down in Alabama [23] I have a dream today [24] I have a dream that one day every valley shall be exalted,

In a paragraph 32 (thirty two) to 39 (thirty nine) from the speech, the anaphora is the world: let the freedom ring. This words is repeated eight times in a paragraph of the speech.

Data number 7:

[32] And so let freedom ring from the prodigious hilltops of New Hampshire. [33] Let freedom ring from the mighty mountains of New York. [34] Let freedom ring from the heightening Alleghenies of Pennsylvania. [35] Let freedom ring from the snow-capped 
Rockies of Colorado. [36] Let freedom ring from the curvaceous slopes of California.

[37] But not only that. Let freedom ring from Stone Mountain of Georgia. [38] Let freedom ring from Lookout Mountain of Tennessee. [39] Let freedom ring from every hill and molehill of Mississippi.

From the idea repetition of anaphore above, there will such a little conclusion about the repetition. The utterances, words or sentences used are: 1) one hundred years later. 2) Now is the time. 3) We must. 4) We can never be satisfied. 5) Go back to. 6) I have a dream, and 7) let freedom ring are the utterances, words or sentences form Martin Luther King Jr. in which repeated many time, more than two. Martin Luther King Jr. wants to show the audiences about that there are still some long way walk to reach, say one hundred years later. It is the goal to share the specific wants (Hudson, 1980). He wants to make sure the audiences that it is now, this is the time, it is a must for us, say Martin Luther King Jr. and the audiences have a dream, the dream must be gained together to goal to be equal, say negro and the goal to have a freedom. It is about the feeling to have a freedom and to be equal.

Furthermore, Chapman (1973) proposes also the idea of repetition, it is about ephistrope. The concept of ephistrope is the use of repetition at the end of successive stages, the repetition happens at the end of utterances.

Back to the speech of Martin Luther King Jr. entitled, "I have a dream." The researcher make 1 (one) citation or data from the speech. That citation or data is in the ideas of repetition. Below is the repetition, in the stage of ephistrope:

In a paragraph 26 (twenty six) from the speech, the ephistrope is the world: with this faith. This words is repeated three times in a paragraph of the speech.

Data number 8:

[26] This is our hope. This is the faith that I go back to the South with. With this faith, we will be able to hear out of the mountain of despair a stone of hope. With this faith, we will be able to transform the jangling discords of our nation into a beautiful symphony of brotherhood. With this faith, we will be able to hew out of the mountain of despair a stone of hope. With this faith, we will be able to transform the jangling discords of our nation into a beautiful symphony of brotherhood. With this faith, we will be able to work together, to pray together, to struggle together, to go to jail together, to stand up for freedom together, knowing that we will be free one day.

The meaning delivered by Martin Luther King Jr. in the speech above that he liked to convey the strong belief about the future, it is about the future he liked to dream about. In a 
previous paragraph of the speech, the dream stated clearly is about the equality, the freedom and of course the togetherness. By saying "with this faith" many times, it was a sign to audiences. There is a faith, there is a belief from their bottom of the heart, a kind of something needs to be pursuid. The repetitions happen to add, to weight the expectation, and also Martin LutherKing Jr. wanted to make this, "with this faith" becomes more memorable, he also used the extention words such as "we will be able to ..." and this is the belief.

The last, Chapman (1973) argues also the idea of repetition, it is about epizeuzis. The concept of epizeuzis is the use of repetition of a word or even phrase in such an utterance, speech to the public in term of continuity of the speech or without having any break at all.

Back to the speech of Martin Luther King Jr. entitled, "I have a dream." The researcher make 1 (one) citation or data from the speech. That citation or data is in the ideas of repetition. Below is the repetition, in the stage of epizeuzis:

In a paragraph 31 (thirty one) from the speech, the epizeuzis is the world: with this faith - this will be the day. This words is repeated one time in a paragraph of the speech.

Data number 9:

[31] And this will be the day - this will be the day when all of God's children will be able to sing with new meaning: My country 'tis of thee, sweet land of liberty, of thee I sing. Land where my fathers died, land of the Pilgrim's pride, from every mountain side, let freedom ring. And if America is to be a great nation, this must become true. And so let freedom ring from the prodigious hilltops of New Hampshire. Let freedom ring from ..."

The focus idea of epizeuzis in repetition is the repetition in continuity, the repetition without having any break at all. The continuity itself refers to the continuity of the ideas. This was used by Martin Luther King Jr. to express that expectation that the expectation is above all. The "this will be the day - this will be the day"expressed that this is the time for us, the audiences to start the struggle, this is day, and this is the time. If it is not now, then it will be when. This utterences like to burn the motivations, like to burn the efforts from the audiences. But luckily the audiences can catch up the meaning delivered. This is actually, the good concept of the rethoric style owned, delivered by Martin Luther King Jr. with the focus of epizeuzis in a repetition.

From all the finding on the concept of repetitions above, the values of the repetition from the speech of Martin Luther King Jr. will be about: 1) the repetition is used to express something more that the meaning itself, it is above the meaning. 2) The the struggle, it is 
something true, true and need to be realized in the real life, and adds the weight of the expection, the expectation to be equal and free.

\section{Conclusions}

From the findings and discussion above, there are some implications based on the study of repetition values on Martin Luther King Jr., the implications reflected through 1) the message conveyed from the speech, it cannot be denied that there are some messages. From the repetition such as: as a) one hundred years later, b) Now is the time, c) We must, d) We can never be satisfied, e) Go back to. f) I have a dream, and g) let freedom ring are the utterances, h) with this faith and i) and this will be the day - this will be the day. Those repetitions reflect their meaning, the meaning is much deeper than the language itself. The meaning sees the context because the speech is connected to the feeling from the speaker to the audiences, the condition of political at that time. Then, the meaning can be drawn as kind of struggle to be free or equal, the expectation. 2) The speech will be always have the implications through the real context situation of that time. So, it means that every single person who does the speech or public speech will not stay in an empty situation.

\section{Acknowledgments}

The expression of salutation in helping to complete this research will always go to my family. With their willingness to sacrifice the fund and the time. My family: thank you for my wife, Zahara Novitasari. My two daughters: Masayu Queenza Poetry Ihsan and Masayu Mareta Cahaya Ihsan.

\section{References}

Asmaradhani, I. (2007). Thesis: Classical Aristotelian Rhetoric Analysis of the American Speeches of the twentieth Century. Surabaya: Pasca Sarjana Unesa.

Badib, A. A. (2010). Materi kuliah pragmatics. Surabaya: Pasca Sarjana Unesa.

Bara, G. B. (2010). Cognitive pragmatics: the mental processes of communication. Cambridge: Massachusette Institute of Technology.

Bradford, R. (1997). Stylistics. Canada: Routledge.

Chapman, R. (1973). Linguistics and Literature: an introduction to literary stylistics. Great 
Britain: T\&A Constable Ltd, Edinburg.

Chomsky, N. (1972). Language and mind. New York: Cambridge University Press.

Creswell, J. W. (2012). Educational Research Planning, Conducting, and Evaluating Quantitative and Qualitative Research (4th ed.). Boston: Pearson.

Fix, U., Gardt, A., \& Knape, J. (2008). Handbooks of Linguistics and Communication Science. Germany: Walter de Gruyter GmbH \& Co.

Gabbay, M. Dov and Woods, J. dZ. (2003). Agenda relevance a study in formal pragmatics. A practical logic of cognitive systems volume 1. UK: Elsevier Science Ltd.

Geurts, B. (1999). Presuppositions and Pronouns. London: Elsevier Science Ltd.

Hudson, R. A. (1980). Sociolinguistics. London: Cambridge University Press.

Mey, J. L. (1993). Pragmatics: an introduction. Massachusetts: Blackwell Publisher Inc.

Schmitz, H.-C. (2008). Accentuation and Interpretation. New York: Palgrave Macmillan.

Toolan, M. (1999). The stylistics of fiction. A literary-linguistics approach.

Yule, G. (1996). Pragmatics. Oxford: Oxford University Press.

Yule, G. (2006). Study of Language. New York: Cambridge University Press. 